\title{
EFFECTS OF LETHAL AND NON-LETHAL MALARIA ON THE MONONUCLEAR PHAGOCYTE SYSTEM *
}

\author{
Carlos Eduardo Tosta ${ }^{1}$, Greta Ruiz, Nina Wedderburn
}

\begin{abstract}
The effects of one non-lethal species of malarial parasite, Plasmodium yoelii, and one lethal species, $\mathrm{P}$. berghei, on the mononuclear phagocyte system (MPS) of $B A L B / c$ mice were studied. P. yoelii caused a greater and more sustained expansion and activation of the MPS, and the two major populations of spleen phagocytic cells-red pulp and marginal zone macrophages - exhibited a greater increase in numbers in this infection. During the course of $\mathrm{P}$. berghei malaria, the spleen was progressively occupied by haematopoietic tissue and, at the terminal stage of infection, an extensive depletion of /ymphocytes and macrophages was apparent.

The possibility was suggested that the outcome of malaria may be influenced by the particular way the parasite interacts with the MPS.
\end{abstract}

(Key-words: Malaria. Plasmodium voelii. Plasmodium berghei. Mononuclear phagocyte System. Macrophages. Monocytes. BALB/c mice).

The mononuclear phagocyte system (MPS) represents a major site of interactions between malarial parasite and the host. During infection, macrophages perform a crucial role in the clearance of parasites ${ }^{2}$, and also appear to play a part in the modulation of the immune response ${ }^{21}$. It is therefore conceivable that the particular way in which this interaction occurs may influence the outcome of the infection. This possibility was investigated in two murine malarias, one lethal caused by Plasmodium berghei, and one self-limiting caused by P. yoelii.

\section{MATERIALS AND METHODS}

\section{Host-parasite systems}

Two to four month old female BALB/c mice bred in our Animal Unit were used throughout this study. They were infected with $10^{5}$ parasitized erythrocytes i.v. of either $P$. yoelii strain $17 \mathrm{X}$ or $P$. berghei ANKA strain, which were maintained as frozen stabilates and passed once in isogenic mice before use. $P$ yoelii $17 X$ causes a self-curing infection after an acute attack lasting 2.3 weeks, while $P$. berghei gives rise to a lethal infection with two peaks of mortality, on days $6-8$ and $21-23$.

\section{Histological techniques}

Livers and spleens were fixed in Carnoy's solution and stained either with haematoxylineosin, Giemsa solution, pyronin-methyl green, and silver impregnation for reticulin 5 . The first two methods were also used for staining the bone marrow.

- Work from the Department of Pathology, Institute of Basic Medical Sciences, London, England, supported by grants from the Cancer Research Campaign of the United Kingdom and Conselho Nacional de Desenvolvimento Cientifico e Tecnológico, Brasil.

1 Present address: Departamento de Medicina Complementar, Universidade de Brasilia, 70.910 Brasflia, Brasil.

Recebido para publicação em 03/01/83 


\section{Spleen cell suspension}

Spleens were minced with a scalpel into cold Hanks' balanced salt solution (HBSS), transferred to siliconized vials containing a magnet and stirred at $4^{\circ} \mathrm{C}$ for $15 \mathrm{~min}$. After sedimentation in the cold, the cells in the supernatant were collected, and the undissociated tissue subjected to two further cycles of stirring and sedimentation. Cells were then washed twice in HBSS, and viability estimated by nigrosin exclusion.

\section{Characterization of macrophages}

Macrophages in cytocentrifuge preparations of spleen and bone marrow were characterized by: (a) nonspecific esterase staining, using alpha-naphthyl acetate as a substrate ${ }^{8}$, and (b) the presence of ingested parasitized and non-parasitized erythrocytes or malarial pigment in Giemsa-stained preparations. In some experiments, macrophages were identified by their characteristic spreading, following the technique of Rabinovitch \& De Stefano ${ }^{14}$. The spreading assay was also used for estimating macrophage activation.

\section{Quantitation of macrophages}

(a) Spleen: the percentage of macrophages in spleen cell suspensions was assessed in esterase-stained cytocentrifuge preparations and their absolute numbers calculated from the number of nucleated spleen cells.

(b) Liver: hepatic sinusiodal cells were identified as those localized alongside the sinusoids, and by their small hyperchromatic nuclei, and their numbers assessed in $5 \mu \mathrm{m}$ thick sections, in relation to 100 parenchymal cells ${ }^{11}$.

(c) Blood: two populations of mononuclear phagocytes were assessed in Giemsa-stained smears of peripheral blood: monocytes (12.8 \pm $1.4 \mu \mathrm{m}$, homogeneous cytoplasm containing no ingested material), and macrophages (15.7 \pm $3.7 \mu \mathrm{m}$, vacuolated cytoplasm containing ingested malarial pigment or parasites).

\section{Analysis of the splenic microarchitecture}

The area of the spleen predominantly occupied by the red pulp, marginal zone, the white pulp (excluding the marginal zone), and the haematopoietic tissue were microscopically evaluated using an eyepiece mounted with a graticule divided into 100 small squares. Each low power microscopical field of a normal spleen covered the width of the cross-section, and comprised one-fifth of its total area. Enlarged spleen were assessed by examining a superficial and a deep area to account for the preferential distribution of certain histological structures, such as the haematopoietic tissue in the periphery of the organ. Results expressed a particular area as the percentage of the total area of the spleen. Structures such as fibrotic tissue and vessels accounted for a maximum of $2 \%$ of the total area.

\section{RESULTS}

The expansion of the mononuclear phagocyte system (MPS)

A significant increase in the number of spleen macrophages in $P$. yoelii malaria was first detected at day 3 of infection. The expansion of this population paralleled the increase in the number of parasitized erythrocytes, reached a maximum by day 10 , and after recovery, the number of macrophages slowly returned to preinfection levels (Fig. 1). In P. berghei infection, macrophages were significantly increased in number on day 3 , but three days later they comprised less than half of their $P$. yoelii counterpart, in spite of the higher parasitaemia. At the final stage of $P$ berghei malaria the number of spleen macrophages decreased sharply.

A significant increase in the numbers of liver phagocytic cells was first detected at day 7 in $P$. yoelii and one week later in $P$. berghei infection (Table 1). This population peaked at day 15 in both infections but while in $P$. yoelii-infected animals the subsequent decrease followed recovery, the drop observed at day 21 of $P$. berghei infection occurred in spite of the rampant parasitaemia (see Fig. 1).

Macrophages containing ingested parasites or malarial pigment were observed in the bone marrow of mice infected by either species from the second week of infection. However, their numbers remained steady throughout the infections.

\section{Macrophage traffic}

In $P$. berghei infection, the numbers of monocytes and macrophages in the peripheral blood increased progressively reaching a peak at day 12, when the former exhibited a 13-fold increase. However, as with spleen and liver 
macrophages, circulating mononuclear phagocytes fell at the end of the infection (Table 2). In the first two weeks of $P$. yoelii infection, circulating monocytes and macrophages underwent quantitative alterations comparable to those of $P$. berghei. Monocytes were the predominant circulating mononuclear phagocyte until day 10, but macrophages predominated thereafter. By day 30 of $P$. yoelii infection no macrophages were detected in the peripheral blood, although monocytes were still found in increased numbers.

The possible migration of macrophages between cell compartments was investigated by assessing the percentage of cells containing malarial pigment in the peritoneal cavity of mice infected intravenously. $\ln P$. berghei infection, $12 \%$ of the population of peritoneal adherent cells contained pigment at day 6 and four days later pigment was observed in only $6 \%$ of peritoneal macrophages, in spite of the greater parasitaemia. In $P$. yoelii-infected mice, pigment-laden peritoneal macrophages (mean of $2 \%$ ) were found exclusively on the tenth day of infection, coincidentally with peak parasitaemia.

\section{Macrophages and the splenic microarchitecture}

Before infection, about $34 \%$ of the total area of the spleen was predominantly occupied by the periarteriolar lymphocytic sheaths and the follicles, $30 \%$ by the red pulp, $19 \%$ by the marginal zone and the remaining $17 \%$ by haematopoietic tissue. However, as infection advanced and anaemia developed, this latter tissue underwent extensive expansion and by day 11 of infection by either species, haematopoietic cells were infiltrating most of the red pulp. compressing the marginal zone against the enlarged white pulp and, indeed, invading this latter area (Fig. 2). In $P$. yoelii-infected mice the splenic microarchitecture returned to normal after recovery, whilst in $P$. berghei infection the haematopoietic tissue expanded progressively and, in the final stage, it comprised most of the area of the spleen (Fig. 2), the spared area of splenic tissue showing extensive macrophage and lymphocyte depletion.

In a parallel study, we assessed the involve. ment of different populations of spleen macrophages in the phagocytosis of parasites at various times after infection. Red pulp macrophages appeared to be the most active in phagocytosis throughout infection by either species
(Table 3). Marginal zone macrophages were active phagocytic cells in $P$. yoelii malaria, whereas in $P$. berghei infection they could not be identified after day 7 because of the extreme subversion of the splenic structure. At the height of the infection by either species, pigment-laden macrophages were observed in the periphery of the white pulp, particularly in the mantle zone of the secondary follicles.

\section{Macrophage activation}

Activation of macrophages was assessed by their degree of spreading after $30 \mathrm{~min}$ incuba. tion at $37^{\circ} \mathrm{C}$. Spreading macrophages were recognized by phase contrast microscopy as large cells showing a prominent cytoplasmic apron and plasma membrane ruffling, and frequently containing ingested material including malarial pigment. As assessed in both Giemsa and in esterase-stained preparations, $23.4 \pm$ $6.7 \%$ of the spleen cells attached to the coverslips were macrophages, $70.0 \pm 6.9 \%$ other mononuclear cells including lymphocytes and haematopoietic cells, and the ramaining $6.2 \pm 3.5 \%$ were polymorphonuclear leucocytes.

As shown in Table 4, the degree and kinetics of the activation of macrophages, as judged by the spreading assay, differed considerably in the two malarial infections investigated. in $P$.: yoelii-infected mice, a highly significant increase in the spreading of both spleen and peritoneal macrophages occurred between days 6 and 30 of infection, peaking at day 10. P. berghei caused a earlier but more moderate, although significant, increase in the degree of spreading, with an apparent drop in the final stage of the infection.

To investigate the possible relationship between the capacity to spread and to phagocytose, macrophages either engaged or not-engag. ed in phagocytosis were collected on day 6 of infection and compared by the spreading assay. Fig. 3 shows that phagocytosing macrophages exhibited a significantly $(p<0.01)$ higher degree of spreading than their non-phagocytosing counterparts in both $P$. yoelii and $P$. berghei infections. Non-phagocytosing macrophages in infected mice showed a degree of spreading comparable to or smaller than that of cells from uninfected mice (Fig. 3). 


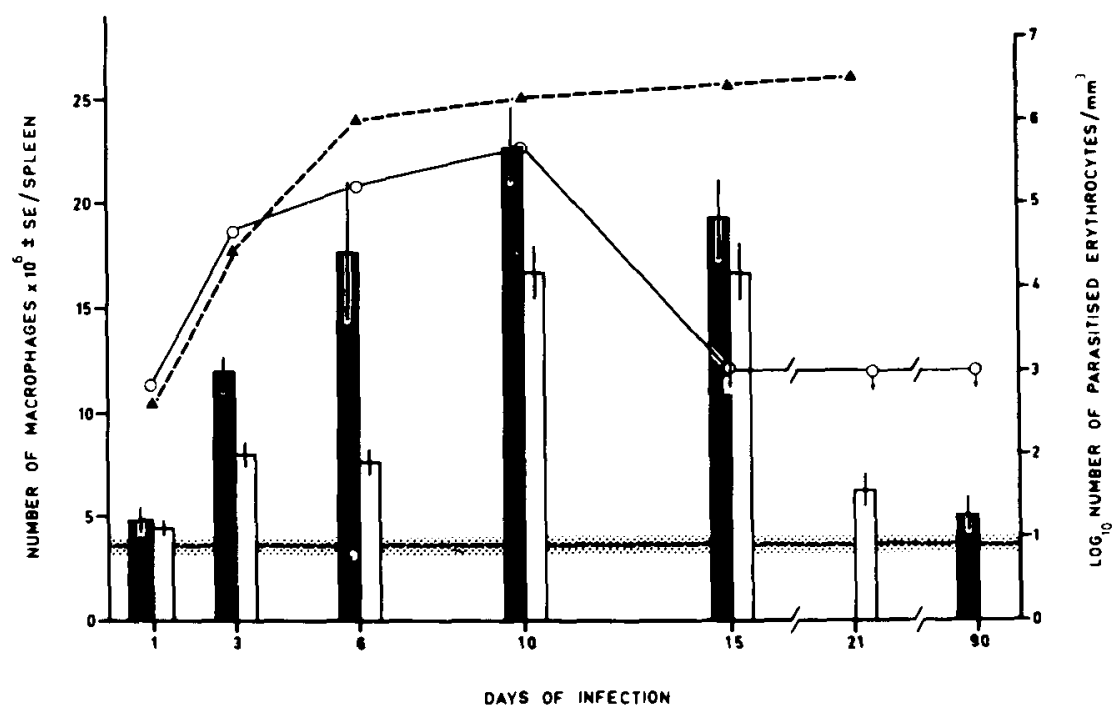

Fig. 1 - Variation in the number of spleen macrophages, and the number of parasitized erythrocytes $/ \mathrm{mm}^{3}$ in $P$. yoelii and $P$. berghei infections in groups of 5 mice.
P. yoelii:
macrophages and

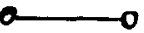
parasitaemia
P. berghei:
macrophages and

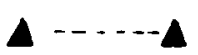
parasitaemia

Shadowed area represents the number of spleen macrophages in non-infected mice \pm standard error.

\section{DISCUSSION}

Spleen, liver and bone-marrow macrophages constitute the main populations of the MPS to react during malaria ${ }^{18}$. The increase in their numbers was therefore considered as an expression of the expansion of the system. The three populations behaved differently: the spleen showed the greatest and most rapid increase in the number of macrophages; liver phagocytic cells exhibited a marked - though delayed expansion, whereas the number of bone marrow macrophages remained steady throughout the infections.

Expansion of the populations of spleen and liver macrophages, accompanied by little or no modification of the bone marrow pool has also been shown by others 17, and probably indicates the degree of involvement of different compartments of the MPS in phagocytosis. Although bone-marrow cells are capable of phagocytosing malarial parasites in vitro ${ }^{6}$, they show a relative inability to ingest blood- borne antigens in vivo ${ }^{9}$. It is possible that the heightened need for macrophages in "shock organs" such as the spleen and the causes an augmented production of phagocytic cells by the bone marrow, which then leave the site.

The relative contribution of the populations of spleen and liver macrophages appeared to vary with the species of parasite. In $P$. voelii malaria the number of spleen macrophages had increased 2.9 times three days after infection and, 7 days later, they averaged $23 \times 10^{6}$ cells/ spleen, corresponding to a 5.7 - fold increase as compared to non-infected nice. A significant expansion of liver sinusoidal cells was only noticed 6 days after infection and peaked 8 days later, when a two-fold increase was observed. Since about $80 \%$ of the liver sinusoidal cells are capable os phagocytosis ${ }^{20}$, and a normal mouse liver contains an average of $9 \times 10^{6} \mathrm{ma}-$ crophages ${ }^{19}$, the peak numbers of liver phagocytic cells observed in $P$. yoelii malaria would be equivalent to $16 \times 10^{6}$ cells, somewhat less than the maximum number of spleen macrophages. 
(A) PYOELII
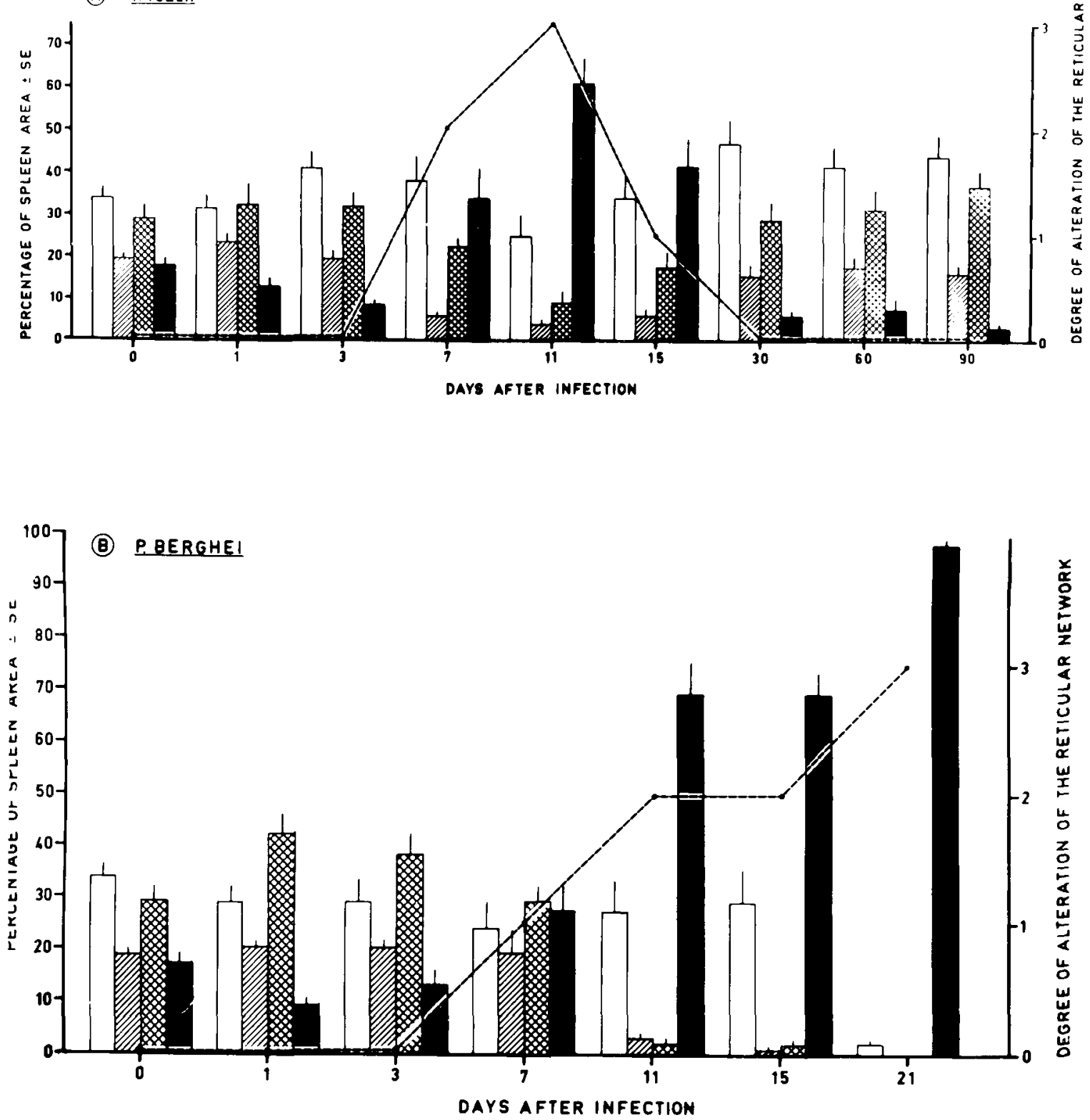

Fig. 2 - Alteration of the splenic microarchitecture during $P$. yoelii (A) and $P$. berghei $(B)$ infections. Data represent the relative areas of the spleen prodominantly occupied by the periarteriolar lymphocytic sheaths and follicles ( $\square$ ), marginal zone ( $\square$ ), red pulp ( $)$ ), and haematopoietic tissue ( 1 ). Data are the mean value of 10 sctions from groups of 5 mice. Line $(\longrightarrow)$ represents the degree of alteration of the reticular framawork, scored from 0 to 3. 


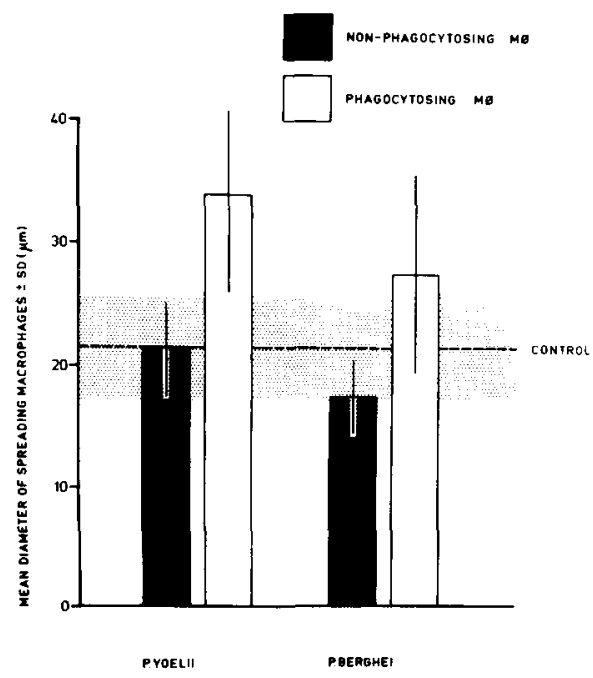

Fig. 3 - Spreading of phagocytosing and non-phagocytosing macrophages. Data represent results from groups of 5 mice. Shadowed area depicts the mean diameter of spread macrophages from uninfected mice \pm standard deviation.

On a quantitative basis, liver phagocytic cells were more important in $P$. berghei - infected mice since they outnumbered spleen macrophages throughout the infection. At the height of the expansion of the MPS, the pool of spleen macrophages was estimated as $16 \times 10^{6}$ cells, whereas the 2.3 - fold increase in the number of liver macrophages would correspond to $19 \times$ $10^{6}$ cells.

It has been recognized that the expansion of the MPS may be due either to recruitment of bone-marrow monocytes or to proliferation in situ. Although macrophage proliferation has been shown to occur under intense stimulation of phagocytosis ${ }^{3}$, this does not appear to be an important factor in the expansion of the MPS in our study. Only very occasionally were sinusoidal lining cells in the liver and, in no instance, were spleen macrophages seen in mitosis during infection, as observed by electronmicroscopy (data not shown). Therefore, the expansion of macrophage populations of the spleen and liver in our study appeared to be mainly due to recruitment from other sites. In fact, Wyler \& Gallin ${ }^{22}$ have shown that accumulation of spleen macrophages in $P$. berghei malaria is associated with the production in situ of monocyte chemotactic factors. Our data showing an increased circulation of mononuclear phagocytes suggest that tissue demand, production and migration of macrophages are associated phenomena, and that redistribution between different compartments may play a part in the expansion of the system. The finding of cells containing malarial pigment in the peritoneal cavity of intravenously infected mice indicates that part of this population originated from another site. In addition, the accumulation of liver phagocyte cells which occurred three or four days after the expansion of spleen macrophages in both $P$. berghei and $P$. yoelii infections suggests that the latter population could be a source of liver phagocytic cells.

We observed in both $P$. yoelii and $P$. berghei infections extensive alterations of the microarchitecture of the spleen, mainly because of the expansion of the haematopoietic tissue, which infiltrated most of the red pulp and invaded the periphery of the white pulp. In $P$. yoelii malaria, the relative area occupied by the white pulp was generally enlarged throughout the infection, whereas in $P$. berghei - infected mice it remained unchanged until the last stages, when it underwent an extensive reduction and finally comprised only $2.5 \%$ of the total area of the spleen, in contrast with $53 \%$ before infection. Furthermore, the few areas of the white pulp not invaded by haematopoietic tissue exhibited marked depletion of macrophages and lymphocytes. This could provide a causal factor for the malaria-induced immunodepression. Spleen lymphocyte depletion has been reported in $P$. berghei infection 7 , and it is probably associated with a progressive loss of the capacity of the organ to retain these cells ${ }^{1}$. Since macrophages have been recognized to play a part in lymphocyte trapping and position- 
ing 410 , it is possible that lymphocyte depletion represents an end-result of the reduction in the population of spleen macrophages.

In our study, both splenic and peritoneal macrophages showed enchanced spreading, which was more marked and more sustained in $P$. yoelii than in $P$. berghei-infected mice. The degree of spreading fluctuated in the animals inoculated with the latter species, despite the continuously increasing parasitaemia, and dropped in the final stages of infection. Shear et al ${ }^{16}$ found that spleen macrophages from $P$. berghei-infected mice underwent a progressive increase in spreading during the infection, whereas peritoneal macrophages showed no change in their ability to spread. The discrepancy between our results and theirs may have several explanations. Shear and her colleagues used a different strain of $P$. berghei, a different criterion for assessing the spreading, and incubated the cells in medium containing serum, which can interfere with the phenomenon ${ }^{14}$. Activation of peritoneal macrophages during the course of an intravenously-induced systemic infection, as shown in our study, has also been reported in mice infected with BCG or Listeria ${ }^{13} 15$ and suggests that either macrophages activated in other sites migrate to the peritoneal cavity and/or that some activating factor is released in the circulation.

On the basis of our own data and of those from other workers, the following sequence of events can be proposed to explain the multiple functions of macrophages in malaria. In the early stages of the infection, spleen macrophages undergo a degree of activation as a consequence of contact with parasites or their products, probably through endocytosis. Activation may induce macrophages to release products (e.g. interleukin 1) that cause lymphocyte proliferation and differentiation. Activated $T$ cells will produce lymphokines which may lead to the recruitment of monocytes, and to a further activation of macrophages. These fully activated macrophages, by means of their enhanced phagocytic capacity, or even some cytotoxic effect towards the parasite, could sometimes control the infections, but it is also possible that an exaggerated phagocytosis could lead to impairment in the accessory function of macrophages and to the release of mediators inhibitory to lymphocyte proliferation. This inhibition could be beneficial for the host if acting on precursors of supressor cells, or on $\mathrm{B}$ cells involved in polyclonal proliferation ${ }^{12}$. Another consequence of the increased phagocytosis could be an augmented release of ironproducts and interference with lymphocyte recruitment and positioning ${ }^{4}$.

It is possible to postulate that in $P$. berghei infection of mice and in other systems in which the course of malaria is severe or fatal, this normal sequence of events may be somewhat altered. We have found that macrophages appear to recognize and ingest $P$. berghe $i$ at a rate comparable to that of $P$. yoelii (C. E. Tosta: unpublished). It seems that the differences in the interaction of each species with the defence system of the host resides at another level of the chain of events triggered by the parasite invasion, for example, the mobilization and activation of macrophages. P. berghei does not seen to have a built-in inability to mobilize and activate the MPS since this can be afforded if parasitaemia is controlled by chemotherapy. Our data indicate that the sequence of events occurs in a slower fashion in $P$. berghei infection, allowing for the relatively unchecked growth of the parasite.

It is suggested that the concept of the tempo of the interaction with the MPS may provide a useful approach to the understanding of hostparasite relationships.

\section{RESUMO}

Estudou-se o efeito da infecção causada por espécie letal (Plasmodium berghei) e nãoletal (P. yoelii) de plasmódio sobre o sistema de fagócitos mononucleares de camundongo $B A L B / c$. O P. yoelii causou maior e mais prolongada expansão e ativação do sistema de macrófagos. As duas mais importantes populações de fagócitos esplênicos - macrófagos de polpa vermelha e da zona marginal - exibiam maior aumento do número de células nesta infecção. Durante a evolução da malária por $\mathrm{P}$. berghei, o baço foi progressivamente ocupado por tecido hematopoiético e, na fase terminal da infecção, observou-se significa tiva depleção dos linfócitos e macrófagos esp/ênicos. Os dados apresentados indicam que a evolução da malária depende do tipo de interação entre o plasmódio e o sistema de fagócitos mononucleares.

(Palavras-chaves: Malária. Plasmodium yoelii. Plasmodium berghei. Sistema de fagócitos mononucleares. Macrófagos. Camundongos BALB/c). 
Tosta CE, Ruiz G, Wedderburn N. Effects of lethal and non-lethal malaria on the mononuclear phagocyte system. Revista da Sociedade Brasileira de Medicina Tropical 16.58.67, 1983

Tabela 1 - Variation in the number of liver sinusoidal cel/s during the course of malaria

\begin{tabular}{c|c|c}
\hline \multirow{2}{*}{ Day } & \multicolumn{2}{|c}{ Sinusoidal cell/100 hepatocytes \pm s.d. $\left({ }^{1}\right)$} \\
\cline { 2 - 3 } & P. yoelii infection & P. berghei infection \\
\hline \multirow{2}{*}{3} & $34 \pm 6$ & $34 \pm 6$ \\
1 & $37 \pm 5$ & $36 \pm 9$ \\
3 & $37 \pm 5$ & $43 \pm 6$ \\
7 & $55 \pm 16\left({ }^{2}\right)$ & $43 \pm 15$ \\
11 & $53 \pm 11\left(^{2}\right)$ & $43 \pm 6$ \\
15 & $67 \pm 20\left(^{2}\right)$ & $77 \pm 20\left({ }^{2}\right)$ \\
21 & $N D$ & $60 \pm 9\left({ }^{2}\right)$ \\
60 & $54 \pm 9\left({ }^{2}\right)$ & $N D$ \\
90 & $35 \pm 9$ & $N D$ \\
\hline
\end{tabular}

(1) Data represent the mean number of cells in three microscopical fields, in groups of 5 mice.

( $\left.{ }^{2}\right)$ Significantly different from day 0 ( $p \leqslant 0.05$ ), Student's ' $t$ ' test.

Tabela 2 - Variation in the numbers of monocytes and macrophages in the peripheral blood of mice infected with $\mathrm{P}$. berghei

Monocytes

Macrophages

Day

$\left(\times 10^{3} / \mathrm{mm}^{3} \pm\right.$ s.d. $)$

$\left(\times 10^{3} / \mathrm{mm}^{3} \pm\right.$ s.d. $)$

$\begin{array}{rlc}0 & 0.26 \pm 0.07\left({ }^{1}\right) & 0 \\ 5 & 0.31 \pm 0.09 & 0.01 \pm 0.01 \\ 7 & 0.69 \pm 0.34\left(^{2}\right) & 0.09 \pm 0.02 \\ 9 & 1.33 \pm 0.23\left(^{2}\right) & 0.67 \pm 0.38 \\ 12 & 3.45 \pm 1.46\left(^{2}\right) & 4.25 \pm 2.90 \\ 19 & 1.11 \pm 0.54\left(^{2}\right. & 1.23 \pm 0.94\end{array}$

(1) Data represent results from groups of 5 mice injected i.v. with $10^{6} P$. berghei-infected erythrocytes.

$\left({ }^{2}\right)$ Significantly different from day $0(p \leqslant 0.05)$, Student's ' $t$ ' test.

Tabela 3 - Involvement of different populations of spleen macrophages in in vivo phagocytosis during the course of malaria

\begin{tabular}{|c|c|c|c|c|c|c|}
\hline \multirow{2}{*}{ Day } & \multicolumn{3}{|c|}{ P. yoelii infection } & \multicolumn{3}{|c|}{ P. berghei infection } \\
\hline & $\begin{array}{l}\text { Red } \\
\text { pulp }\end{array}$ & $\begin{array}{c}\text { Marginal } \\
\text { zone }\end{array}$ & $\begin{array}{l}\text { White } \\
\text { pulp }\left({ }^{1}\right)\end{array}$ & $\begin{array}{l}\text { Red } \\
\text { pulp }\end{array}$ & $\begin{array}{c}\text { Marginal } \\
\text { zone }\end{array}$ & $\begin{array}{l}\text { White } \\
\text { pulp }\end{array}$ \\
\hline 1 & - & - & - & - & - & - \\
\hline 3 & $+\left({ }^{2}\right)$ & - & - & - & - & - \\
\hline 7 & ++ & + & - & $+t+$ & + & - \\
\hline 11 & +++ & +++ & + & ++ & + & - \\
\hline 15 & +++ & $++t$ & - & ++ & + & $+t$ \\
\hline 21 & ND & ND & ND & $++t$ & $-\left(^{3}\right)$ & ++ \\
\hline 30 & +++ & ++ & - & ND & ND & ND \\
\hline
\end{tabular}

(1) Excluding the marginal zone.

(2) Data represent the results from groups of 5 mice

The frequency of macrophages containing malarial pigment per area of spleen was scored from $(-)$ to $3(+)$

${ }^{3}$ ) Splenic microarchitecture markedly disrupted by the growth of haematopoietic tissue; no marginal zone identified. 
Tabela 4 - Variation in the spreading of spleen and peritoneal macrophages during intravenously - induced malaria

\begin{tabular}{|c|c|c|c|c|}
\hline \multirow{2}{*}{ Day } & \multicolumn{2}{|c|}{ P. yoelii infection } & \multicolumn{2}{|c|}{ P. berghei infection } \\
\hline & Spleen $M \emptyset$ & Peritoneal MO & Spleen MØ & Peritoneal $M \emptyset$ \\
\hline 0 & $20.0 \stackrel{\times}{\div} 1.4\left(^{1}\right)$ & $18.6 \stackrel{\times}{\div} 1.5$ & $20.0 \stackrel{\times}{\div} 1.4$ & $18.6 \stackrel{x}{\div} 1.5$ \\
\hline 3 & $20.0 \stackrel{x}{\div} 1.4$ & $24.0 \stackrel{\div}{\div} 1.3\left(^{2}\right)$ & $23.4 \stackrel{\dot{x}}{\div} 1.4\left(^{2}\right)$ & $31.6 \stackrel{x}{\div} 1.3\left(^{2}\right)$ \\
\hline 6 & $31.6 \stackrel{\bar{x}}{\dot{x}} 1.3\left(^{2}\right)$ & ND & $25.7 \stackrel{\bar{x}}{\dot{x}} 1.3\left(^{2}\right)$ & $24.5 \stackrel{x}{-} 1.4\left(^{2}\right)$ \\
\hline 10 & $33.1 \stackrel{\bar{x}}{\underline{x}} 1.4\left(^{2}\right)$ & $33.1 \stackrel{\times}{\stackrel{x}{-} 1.4\left(^{2}\right)}$ & $23.4 \stackrel{\bar{x}}{\dot{x}} 1.3\left(^{2}\right)$ & $31.6 \stackrel{\dot{x}}{-} 1.5\left(^{2}\right)$ \\
\hline 15 & $29.5 \stackrel{\bar{x}}{\dot{x}} 1.5\left(^{2}\right)$ & $25.7 \stackrel{\dot{x}}{\dot{x}} 1.5\left(^{2}\right)$ & $26.9 \stackrel{\bar{x}}{-} 1.3\left(^{2}\right)$ & ND \\
\hline 21 & $\overline{N D}$ & ND & $22.9 \underline{x} 1.3\left(^{2}\right)$ & ND \\
\hline
\end{tabular}

(1) Data represent geometric mean $(\mu \mathrm{m}) \stackrel{x}{\div}$ standard deviation of the major diameter of spreading macrophages from groups of 5 mice.

$\left.{ }^{2}\right)$ Significantly different $(p \leqslant 0.001$ ) from day 0, Student's " $t$ " test.

\section{ACKNOWLEDGEMENTS}

The authors are grateful to Biddy Adkins, John Manders and Glen Vallint for expert technical assistance and to Jane Araújo for the preparation of the manuscript.

\section{REFERENCES}

1. Brissette WH, Coleman RM, Rencricca NJ Depressed splenic $T$ lymphocyte numbers and thymocyte migratory patterns in murine malaria. Proceedings of the Society for Experimental Biology and Medicine 159: 317-320, 1978.

2. Brown KN, Brown IN, Trigg PI, Phillips RS, Hills LA. Immunity to malaria. II. Serological response of monkeys sensitized by dead parasitized cells in Freund's complete adjuvant. Experimental Parasitology 28:318-338, 1970.

3. Deinmann W, Fahimi HD. The appearance of transition forms between monocytes and Kupffer cells in the liver of rats treated with glucan. A cytochemical and ultrastructural study. Journal of Experimental Medicine 149:883-897, 1979.

4. de Souza M. Lymphoid cell positioning: a new proposal for the mechanisms of control of lymphoid cell migration. In: Cell- cell recognition, Symposium n? 32 , Society for Experimental Biology, p 393-409, Cambridge University Press, Cambridge, 1978.

5. Disbrey RD, Rack JH. Histological laboratory methods. E \& S Livingstone, Edinburgh, 1970.

6. Frankenburg S, Londner MV, Greenblatt $\mathrm{CL}$. Cellular changes in the bone marrow of Plasmodium berghei-infected mice. II. Blast transformation and phagocytosis. Cellular Immunology 55:185-190, 1980.

7. Fres:man RR, Parish CR. Spleen cell changes during fatal and self-limiting malarial infections of mice. Immunology 35:479. 484, 1978.

8. Horwitz DA, Allison AC, Ward P, Knight N . Identification of human mononuclear leu-

cocyte populations by esterase staining. Clinical and Experimental Immunology 30:289-298, 1977.

9. Humphrey JL. Marginal zone and marginal sinus macrophages in the mouse are distinct populations. Advances in Experimental Medicine and Biology 114:381-388, 1979.

10. Humnhrey JL. Macrophages and the diffe- 
rential migration of lymphocytes. In: Blood cells and vessel walls: functional interactions. Ciba Symposium n? 71, p 287-296, Ciba Foundation, London, 1980.

11. Kelly LS, Brown BA, Dobson EL. Cell division and phagocytic activity in the liver reticulo-endothelial cells. Proceedings of the Society for Experimental Biology and Medicine 110:555-559, 1962.

12. Lelchuk R, Playfair JHL. Two distinct types of non-specific immunosuppression in murine malaria. Clinical and Experimental Immunology 42:428-435, 1980.

13. North RJ. Cellular kineties associated with the development of acquired cellular resistance. Journal of Experimental Medicine $130: 299-311,1969$.

14. Rabinovitch $M$, de Stefano MJ. Macrophage spreading in vitro. I. Inducers of spreading. Experimental Cell Research 77:323$334,1973$.

15. Rhodes JM, Bennedsen J, Riisgaard S, Larsen SO. Intracellular killing, degradation, metabolic activity, and increase in betagalactosidase activity as markers for activated macrophages. In: $R$ van Furth (ed) Mononuclear phagocytes. Functional aspects. Martinus Nijhoff, The Hague, $p$ 1743-1757, 1980.

16. Shear HL, Nussenzweig RS, Bianco $C$. Immune phagocytosis in murine malaria.
Journal of Experimental Medicine 149: 1288-1298, 1979.

17. Singer I. The cellular reactions to infections with Plasmodium berghei in the white mouse. Journal of Infectious Diseases 94: 241-261, 1954.

18. Taliaferro $W H$, Mulligan HW. The histopa thology of malaria with special reference to the function and origin of the macrophages in defence. Indian Medical Research Memories 29:1-138, 1937.

19. van Furth $R$, Diesselhoff-den Dulk MMC, Raeburn JA, van Zwet TL, van Oud Alblas AB. Characteristics, origin and kinetics of human and murine mononuclear phagocytes. In: $R$ van Furth (ed) Mononuclear phagocytes. Functional aspects. Martinus Nijhoff, The Hague, p 279-298, 1980.

20. Widmann JJ, Cotran RS, Fahimi HD.Mononuclear phagocytes (Kupffer cells) and endothelial cells: identification of two functional œll types in rat liver sinusoids by endogenous peroxidase activity. Journal of Cell Biology 52:159-170, 1972.

21. Wyler DJ. Cellular aspects of immunoregulation in malaria. Bulletin of the World Health Organization 57:239-243, 1979.

22. Wyler DJ, Gallin JI. Spleen-derived mononuclear cell chemotactic factor in malaria infections: a possible mechanism for splenic macrophage accumulation. The Journal of Immunology 118:478-484, 1977. 